\title{
Fatores biopsicossociais do profissional estriador de resina e suas condições de trabalho
}

\section{Factor biopsychosocial of resin scriber professional and your working conditions}

\author{
Fatores biopsicosociales del profesional estriador de la \\ resina y sus condiciones de trabajo
}

Nelson Kian ${ }^{1}$

Daniela Gonçalves Marques Lacerda² Mariana Buque Sanchez ${ }^{3}$ Paola Alves Fernandes ${ }^{4}$

${ }^{1}$ Graduado em Fisioterapia pela Instituição Municipal de Ensino Superior de Presidente Prudente (IMEESPP); Especialista em Métodos e Técnicas de Ensino Superior (CESUP), em Fisioterapia Traumato Ortopédica Funcional pelo Conselho Regional de Fisioterapia e Terapia Ocupacional (COFFITO) e mestrado em Psicologia pela Universidade Católica Dom Bosco (UCDB). Professor titular na Universidade Católica Dom Bosco(UCDB), na Faculdade de Campo Grande (FCG) e na Faculdade Mato Grosso do Sul (FACSUL). Professor titular na Pós-graduação (lato sensu) na Faculdade INSPIRAR e no Instituto de Educação e Pesquisa Alfredo Torres (IEPAT). E-mail: nelkian@yahoo.com.br.

${ }^{2}$ Acadêmica do curso de Fisioterapia da UCDB. E-mail: daniglacerda@hotmail.com

${ }^{3}$ Acadêmica do curso de Fisioterapia da UCDB.

E-mail: marianabuque@hotmail.com

${ }^{4}$ Acadêmica do curso de Fisioterapia da UCDB.

E-mail: papafernandes@hotmail.com 
Resumo: A matéria-prima da resina é um importante produto de exportação no Brasil. A técnica de resinagem consiste em várias etapas, sendo o estriador um elemento essencial nesse processo de extração. O objetivo deste estudo foi identificar os riscos ocupacionais do profissional Estriador de resina, bem como suas condições de trabalho e questões preventivas. Trata-se de um estudo de caso, no qual os dados foram colhidos por meio de uma entrevista com roteiro semiestruturado contendo dados demográficos, dados profissionais, fatores de risco, agravos à saúde e os aspectos biopsicossociais. Posteriormente os resultados foram comparados com a Norma Regulamentadora 31 (NR13) para sua profissão, com a Consolidação das Leis Trabalhistas (CLT) e artigos científicos. Os resultados demonstraram que a empresa apresenta pontos positivos quanto ao cumprimento da Consolidação das Leis Trabalhistas e normas de seguranças, mas negativos quanto ao sistema de transporte do trabalhador. Contudo esse trabalhador consegue se adequar em todos os aspectos biopsicossociais.

Palavras-chave: saúde do trabalhador; extração de resina; estriador; Consolidação das Leis do Trabalho; setor florestal.

Abstract: The raw material of the resin is an important export product in Brazil. The resin technique consists of several steps, being the scriber an essential element in this extraction process. The aim of this study is to identify the occupational risks of the resin scriber professional, as well as his working conditions and preventive issues. This article presents a study case in which the data was collected by an interview guided with a semi-structured script containing demographic data, professional data, risk factors, health issues and biopsychosocial aspects. Later, compared with the Regulatory standard (NR31) for his profession, the Brazilian work laws and scientific articles. The results demonstrated that the company in question presents positive topics concerning the execution of work laws and safety standards, but negatives ones about the worker's transportation. However, this worker can adapt himself in all biopsychosocial aspects.

Key words: worker health; resin extraction; resin scriber professional; Consolidation of the Labor Laws; forestry sector.

Resumen: La materia prima de la resina es un product de exportación importante en Brasil. La técnica de resina consiste en varios pasos, siendo el estriador un elemento esencial en este proceso de extracción. Este estudio tiene como objetivo identificar los riesgos laborales del profesional estriador de la resina, así como sus condiciones de trabajo y cuestiones preventivas. En este artículo se presenta un estudio de un caso en el que se administró un cuestionario en formato de entrevista que contiene sus datos demográficos, datos profesionales, factores de riesgo, agravos de salúd y aspectos biopsicosociales. Posteriormente, los resultados en comparción com las Normar Regulamentaria 31 para su profesión, lo Estatuto de los Trabajadores y artículos científcos. Los resultados mostraran que la empresa, tenían puntos positivos quanto al cumplimiento de los derechos laborales y normas del seguridad, pero negativos quanto el sistema del transporte del trabajador. Además, el trabajador puede adecuarse en todos los aspectos biopsicosociales.

Palabras clave: salud ocupacional; extraccíon de resina; profesional estriador; Estatuto de los Trabajadores; sector florestal. 


\section{INTRODUÇÃO}

O agronegócio é um importante setor na economia nacional, em cujo contexto o campo florestal está inserido como um segmento relevante. Com a crescente devastação das florestas nativas brasileiras e, concomitantemente, a grande demanda de produtos florestais, houve a necessidade de florestar e reflorestar grandes áreas, em que foram implantados principalmente o Eucaliptus e o Pinus.

O Brasil se tornou um importante exportador de papel, celulose e diversos outros produtos derivados da madeira devido à implantação de florestas homogêneas de espécies de crescimentos rápido e pela verticalização de empresas de grande porte. É possível incluir também uma gama de produtos florestais não madeireiros existentes nas florestas, que vão das plantas aos animais. Existe um leque muito amplo como, por exemplo, obtenção de produtos de raízes, troncos, cascas, folhas, flores, sementes, frutos, entre outros.

A resinagem em termos mundiais vem sendo quimicamente estimulada desde a década de 1970. Já, no Brasil, teve início na década de 1980 em florestas de Pinus elliottii com a utilização de incentivos fiscais das décadas de 1960 e 70, com a Lei Federal n. 5.106, de 1.966 (BRASIL, 1966 ).

Atualmente, o Brasil, junto com a Indonésia, compõe o segundo lugar em exportação mundial de goma resina, com produção anual de 124 mil toneladas e geração de cerca de 15 mil empregos diretos e indiretos, sendo que a China ocupa o primeiro posto nesse ranking (RODRIGUES, 2008).

A resina pode ocorrer tanto em coníferas quanto em folhosas. A maioria das folhosas contém menos de $1 \%$ de resina, enquanto que as coníferas geralmente possuem maiores teores, particularmente o gênero Pinus. Dentre as coníferas, como maiores produtores de resina, destacam-se os gêneros Abies, Picea e Pinus. Entretanto o gênero 
Pinus é o de maior importância, destacando as seguintes espécies: Pinus Elliotti, Pinus Caribaea, Pinus Pallustris, Pinus Pinaster, Pinus Taeda e Pinus Sylvestris (BRITO; BARRICHELO, 1978).

A técnica de resinagem consiste primeiramente na escolha da árvore, depois na limpeza do tronco, utilizando "raspador de tronco", para que a superfície da árvore fique lisa; confecção do bigode, incisão ao redor da árvore para que seja empregado o recipiente coletor; colocação do recipiente. Estriagem corresponde a $80 \%$ do sucesso do empreendimento, por meio de um instrumento chamado "ferro estriador", fazendo-se um corte em faixa para escorrer a goma-resina e, por fim, a estimulação química, com a utilização de pasta ácida com a finalidade de aumentar a exsudação da resina, aplicada em todas as estrias individualmente. Posteriormente, é realizada a coleta e transferida a produção para tambores protegidos em todo seu interior com saco plástico, para evitar oxidação do material.

O resultado desse processo por decantação e destilação, que se inicia em média oito anos após sua plantação, é o breu (fase sólida) e a terebintina (fase líquida) que apresentam grande importância nas indústrias na fabricação de fármacos, cosméticos, ingredientes de limpeza, borrachas sintéticas, tintas de impressora, colas, entre outros (POLYQUIM, 2016).

A goma-resina é uma "commodity", e seu preço oscila constantemente, sem qualquer regulamentação. É vendida por quilo e, por esse motivo, os bons profissionais que trabalham em sua extração são essenciais, desde as estrias, instalação de saquinhos sem vazamentos até a coleta e sua pesagem. Historicamente, a grande dificuldade relacionada à esse setor, sempre foi o déficit de trabalhadores disponíveis para se submeter a tal condição física que é exigida para desempenhar a função, pois é um trabalho puramente braçal e árduo, em que um trabalhador normalmente caminha em média cinco quilômetros por dia (LEITE, 2014). 
Nesse contexto específico, este trabalho tem por objetivo identificar quais os riscos ocupacionais do profissional Estriador de resina, bem como suas condições de trabalho envolvendo todos os aspectos (químicos, físicos, organizacionais e psicossociais) e questões preventivas.

\section{MATERIAIS E MÉTODOS}

Este trabalho teve sua produção no decorrer do mês de maio de 2016. Em um primeiro momento, ocorreu a discussão e escolha de qual profissão seria abordada; diante das diversas opções, selecionou-se o Estriador de resina, no qual foi observado que, durante o exercício de sua atividade, estava exposto a diversas situações de risco. O conhecimento dessa profissão se deu pelo contato de um dos autores com esse profissional, em uma Clínica particular de fisioterapia, na qual estava em tratamento devido à lombalgia. Posteriormente, foram realizadas diversas pesquisas em busca de literatura pertinente sobre a saúde do trabalhador no geral e todos os aspectos que envolvem a extração de resina.

Devido à dificuldade de acesso a estes profissionais, por atuarem em àreas rurais, optou-se por um estudo de caso. Um check-list foi formulado pela equipe contendo 37 questões abertas e fechadas, abordando informações pessoais, os aspectos econômicos, os relacionados ao trabalho e os psicossociais. Já realizado o primeiro contato com o profissional e o check-list estruturado, este foi aplicado em forma de entrevista.

A pesquisa foi realizada em uma fazenda de pequeno porte, localizada na cidade de Ribas do Rio Pardo, MS, onde há atividade de resinagem e o profissional que participa do processo de extração de goma resina, denominado estriador.

Seguindo o processo de construção deste estudo, os resultados obtidos foram discutidos e analisados segundo as normas regulamentadoras da profissão (NR31), a Constituição Federal de 1988 (CF/88) 
e a Consolidação das Leis Trabalhistas (CLT), com foco na atividade realizada pelo estriador, bem como seus riscos, formas de prevenção que Ihe são oferecidas, transporte e ainda a relação com sua família, situação econômica e seu entendimento sobre os danos que sua atividade profissional poderá Ihe causar futuramente (BRASIL, 2001; BRASIL, 1988; BRASIL, 1943).

\section{RESULTADOS E DISCUSSÃO}

O profissional estriador de resina participante trabalha em uma fazenda de pequeno porte localizada no município de Ribas do Rio Pardo, MS, onde se encontram trabalhadores do gênero masculino e feminino, com predominância masculino. Nesta pesquisa, participou apenas um profissional, do gênero masculino, de 22 anos, casado, com ensino fundamental incompleto e renda que varia aproximadamente entre um e três salários mínimos, dependendo de sua produção mensal. Esta é a sua única fonte de renda, da qual dependem sua filha e esposa.

Trabalha nesse ramo há quatro anos e já foi supervisor na área de extração. Sua jornada de trabalho é integral, de oito horas por dia, de segunda a sexta, totalizando 40 horas semanais.

Conforme cita o Ministério do Trabalho e Emprego (MTE), a jornada de trabalho normal se dá durante o espaço de tempo no qual o empregado deverá prestar serviço ou permanecer à disposição do empregador e, nos termos da CF, art. 7으, XIII, sua duração deverá ser de até 8 horas diárias, e 44 horas semanais; sendo assim, as horas trabalhadas estão compativeis com as normas regulamentadoras.

Segundo a Norma Regulamentadora 31 (NR31), que visa garantir que os empregadores forneçam condições aos trabalhadores por meio do estudo do ambiente, adotando medidas para controle dos riscos para preservar a saúde e a integridade física dos colaboradores no 
trabalho rural, é necessário que também ocorra uma boa gestão em segurança e saúde no campo.

A CF/88 proporciona um aval a NR31 ao definir uma série de responsabilidades para os empregadores, no que diz respeito à segurança e à saúde no trabalho de seus empregados. Dentre elas, podemos citar: os empregadores devem conhecer os riscos de suas atividades ambientais e os de acidentes de trabalho, como também, informar aos trabalhadores sobre os riscos para prevenir e limitar tais riscos (SILVEIRA, 2009, LAZIA, 2012).

Quanto ao uso de Equipamentos de Proteção Individual (EPI'S), o trabalhador afirma fazer uso de botas, luvas e roupas adequadas para exercer sua função e que a empresa disponibiliza tais equipamentos e reforça o uso destes, com avisos sobre seu uso obrigatório, questões estas normatizadas pela NR31. Essa norma enfatiza que esses EPI's devam ser fornecidos pelo empregador, e este, deva ser o responsável em supervisionar seu uso. Os equipamentos fornecidos devem estar em perfeitas condições de uso e conservação, sem custo algum ao funcionário e adequados às funções exercidas por ele, que tem por obrigação zelar por esses equipamentos.

Foi verificado que não há cumprimento em relação a guarda e transporte dos instrumentos cortantes e quanto ao uso de máscara e óculos de proteção, uma vez que seu ambiente de trabalho é rural e ele faz uso de pasta ácida para aumentar a eficácia da extração. Segundo a NR31 normatiza que os instrumentos cortantes devem ser guardadas e transportadas em bainhas e permanecer afiadas. Assim, segundo a classificação de Silveira (2009), esse trabalhador está exposto aos riscos químicos (agentes e substâncias químicas sob forma de líquidos, gases, vapores, névoas, neblina, fumos, poeiras, fibras), aos riscos decorrentes da organização do trabalho (falhas no treinamento e na supervisão de trabalhadores) e riscos mecânicos e de acidente (inadequação e falta de proteção no transporte de instrumentos cortantes). 
Conforme questionamento sobre o tempo até seu local de trabalho, esse trabalhador relata que o transporte é oferecido pela empresa e que o deslocamento ao local demora aproximadamente uma hora. Relata ainda que o ônibus disponibilizado para a locomoção dos trabalhadores é de péssima condição. Segundo a Súmula n. 90 do Tribunal Superior do Trabalho, está estabelecido que:

HORAS "IN ITINERE". TEMPO DE SERVIÇO (Incorporadas as Súmulas № 324 e 325 e as Orientações Jurisprudenciais № 50 e 236 da SBDI-1) - Re. 129/2005 - DJ 20.04.2005 I- O tempo despendido pelo empregado, em condução fornecida pelo empregador, até o local de trabalho de difícil acesso, ou não servido por transporte público regular, e para o seu retorno é computável na jornada de trabalho. (Ex- Súmula № 90 - RA 80/78, DJ 10.11.1978). II - A incompatibilidade entre os horários de início e término da jornada do empregado e os do transporte público regular é circunstância que também gera o direito às horas "in itinere". (Ex-OJ № 50 - Inserida em 01.02.1995). III- A mera insuficiência de transporte público não enseja o pagamento de horas "in itinere". (Ex-Súmula № 324 - RA 16/1993, DJ 21.12.1993). IVSe houver transporte público regular em parte do trajeto percorrido em condução da empresa, as horas "in itinere" remuneradas limitam-se ao trecho não alcançado pelo transporte público. (Ex - Súmula № 325 RA 17/1993, DJ 21.12.1993). V- Considerando que as horas "in itinere" são computáveis na jornada de trabalho, o tempo que extrapola a jornada é considerado como extraordinário e sobre ele deve incidir o adicional respectivo (Ex-OJ № 236 - Inserida em 20.06.2001). (BRASIL, 2005).

Portanto não cabe como direito, nesse caso, que o trabalhador tenha algum benefício ou acréscimo em seu salário devido ao tempo que é despendido desde a saída da cidade até o seu local de serviço, uma vez que a empresa disponibiliza o transporte necessário e que se encontra em consonância com a NR31.

Como relatado pelo trabalhador, as condições de transporte são bastante precárias, o que pode contribuir com o que Silveira (2009) 
classifica como acidente de trajeto, quando esses acidentes ocorrem no percurso de casa para o trabalho ou vice-versa, não importando o meio de locomoção, mas relacionados com as condições de transporte dos trabalhadores e violência do trânsito nos grande centros urbanos.

Segundo a CLT, em seu Art. 71:

Art. 71- Em qualquer trabalho contínuo, cuja duração exceda de 6 (seis) horas, é obrigatória a concessão de um intervalo para repouso ou alimentação, o qual será, no mínimo, de 1 (uma) hora e, salvo acordo escrito ou contrato coletivo em contrário, não poderá exceder de 2 (duas) horas.

$\S 3$ 3- O limite mínimo de 1 (uma) hora para repouso ou refeição poderá ser reduzido por ato do Ministro do Trabalho quando, ouvida a Secretaria de Segurança e Higiene do Trabalho, se verificar que o estabelecimento atende integralmente às exigências quando os respectivos empregados não estiverem sob regime de trabalho prorrogado a horas suplementares (Decreto-lei no 229, de 28-02-67, DOU 28-02-67). (BRASIL, 1943).

O trabalhador possui hora de almoço adequado ao que a CLT prevê de, no mínimo, uma hora, porém, faz uso de apenas 15-20 minutos, devido a dependência dele para com sua produção na extração de resina, fator esse que interfere diretamente em sua renda ao final do mês. Durante seu expediente realiza mais de três pausas.

Trabalha predominantemente na posição em pé ao realizar as estrias nos troncos das árvores, e não são disponibilizadas e/ou planejadas alternativas para prevenção de dores ou lesões, como orientações de posturas adequadas, massagem, alongamento, entre outros. Por esses motivos, acredita-se que esse trabalhador estava em atendimento fisioterapêutico devido à lombalgia. Esse quadro contraria a Norma Regulamentadora 17 (NR17) referente à ergonomia, que estabelece que o empregador deva adotar princípios ergonômicos de modo a proporcionar melhorias nas condições de conforto e segurança do trabalho; inclui também as pausas para os trabalhadores 
que exercem sua função necessariamente em pé e, além das pausas, outras medidas que preservem a saúde do trabalhador que tenha sobrecarga muscular ou dinâmica devem ser realizadas.

Quanto aos direitos trabalhistas que lhe são assegurados, afirma receber todos sem empecilho algum. A empresa não oferece nenhum tipo de treinamento específico e/ou reciclagem, mas o trabalhador julga-o necessário para que não ocorram erros nem desperdícios no processo, o que acarreta prejuízos na produção final da goma resina, porém as empresas não possuem a responsabilidade de assegurar tais vantagens nesse setor.

Considerando todos os aspectos envolvidos no processo saúde-doença do trabalhador, fez-se necessário abordar também as questões pessoais, como a qualidade e tempo de sono, que esse trabalhador considera boa, dormindo oito horas por dia, que seu quarto é escuro e silencioso o suficiente para que consiga dormir de modo que acorde descansado. Fato que é de extrema importância, tendo em vista que sua atividade exige muita atenção e alerta.

Segundo Varella (2011), trabalhos feitos experimentalmente demonstraram que o sono nos mamíferos é eficaz no combate às infecções, para o cérebro processar informações, armazenar dados, elaborar estratégias importantes para o seu convívio na sociedade. Com isso, o trabalhador ter um sono adequado é fundamental para que ele associe o sono com o bom resultado diante das tarefas executadas no período de trabalho e suas relações interpessoais.

Nesses mesmos aspectos, aponta ainda possuir uma boa relação com sua família, pois aproveita seu tempo disponível com programas junto a sua filha e esposa, além de praticar seu hobbie, como mecânico, aos finais de semana.

Apesar de não praticar nenhuma atividade física, possui uma vida ativa junto de sua família e amigos, consegue desfrutar de momentos de lazer com ambos de maneira que seu trabalho não venha 
a interferir de maneira negativa em suas relações interpessoais, visto que não considera sua atividade profissional estressante.

\section{CONSIDERAÇÕES FINAIS}

Ao final desta pesquisa, os resultados apontaram que a matéria-prima da resinagem é uma atividade bastante significativa no contexto econômico-social brasileiro, e o profissional estriador de resina exerce papel de grande importância no processo de extração da goma resina, sendo necessário ter bons profissionais para essa prática no setor florestal para não haver prejuízos. Todavia seu ambiente de trabalho oferece riscos à sua saúde que podem não estar evidenciados neste momento, mas que podem futuramente gerar desgastes tanto físicos quanto emocionais, advindos das longas caminhadas diárias e da necessidade do fator produção do qual ele é dependente, uma vez que é sua única fonte de renda, e qualquer dia perdido significa prejuízo.

A empresa possui pontos positivos, tais como a oferta dos EPI'S em bom estado de conservação e o cumprimento de todos os direitos trabalhistas.

Contudo existem os pontos negativos que ficaram evidenciados, num primeiro momento, o transporte que a empresa oferece para o percurso dos trabalhadores até o local do serviço encontra-se em condições precárias e de risco; existe a falta de propostas ergonômicas que têm a finalidade de prevenir eventuais lesões pelo esforço e garantir a saúde desse trabalhador. Igualmente, a inexistência de capacitações, treinamentos e/ou reciclagens em todas as etapas do processo deveriam estar incluídas para qualificação da mão de obra, o que a longo prazo evitaria desperdícios e, consequentemente, maior efetividade na coleta da resina, refletindo de maneira positiva em aumento do lucro pelo empregador. 
Além disso, não foram encontradas literaturas que abordassem uma visão integral do trabalhador na extração de resina, mas apenas questões referentes ao aspecto econômico e lucrativo gerado nesse setor, indicando a necessidade de estudos futuros quanto aos fatores de risco e condições de trabalho envolvidos nessa atividade.

Devido à impossibilidade de comunicação com o profissional entrevistado durante o desenvolvimento da pesquisa, algumas questões não foram completamente esclarecidas. O primeiro ponto que deixou de ser esclarecido está relacionado à supervisão do uso de EPI'S por parte de alguém responsável, outro aspecto colocado em questão é referente ao material usado para confecção das estrias, o qual deve estar sempre afiado e guardado em bainhas. Quanto ao horário de almoço e as pausas realizadas durante o expediente, é necessário que haja um local específico com boa estrutura, composto de instalações sanitárias, locais para refeição e preparo de alimentos, condições adequadas de higiene, iluminação e ventilação, fator esse para o qual não obtivemos resposta em relação aos componentes que são exigidos, sabe-se apenas que existe um local reservado para os momentos em que não está realizando sua função.

O reconhecimento da existência desses fatores de risco em uma situação de trabalho do estriador é fundamental para a definição da existência ou não da situação de risco para esse trabalhador.

\section{REFERÊNCIAS}

BAENA, E. de S. Análise da viabilidade econômica da resinagem em Pinus elliottii Engelm. Var. elliottii nas regiões sul do Estado do Paraná e sul e sudoeste do estado de São Paulo. 1994. 94 f. Tese (Doutorado em Ciências Florestais/ Engenharia Florestal)- Universidade Federal do Paraná, Curitiba, 1994.

BRASIL. Ministério do Trabalho e Emprego (MTE). Leis e direitos trabalhistas. [s.d.]. Disponível em: <http://portal.mte.gov.br/ouvidoria/duvidastrabalhistas/>. Acesso em: 19 maio 2016. 
. Tribunal Superior do Trabalho. Súmula n. 90. Horas "IN ITINERE". Tempo de Serviço (incorporadas as Súmulas n. 324 e 325 e as Orientações Jurisprudenciais n. 50 e 236 da SBDI-1) - Res. 129/2005, DJ 20, 22 e 25.04.2005 . 2005. Disponível em: <http://www3.tst.jus.br/jurisprudencia/ Sumulas_com_indice/Sumulas_Ind_51_100.htmI\#SUM-90>. Acesso em: 2 maio 2016.

- Ministério do Trabalho e Emprego. NR 31 - Segurança e Saúde no Trabalho na agricultura, Pecuária Silvicultura, Exploração Florestal e Aquicultura. Brasília: Ministério do Trabalho e Emprego, 2001. Disponível em: <http://www.guiatrabalhista.com.br/legislacao/nr/nr31.htm\#31.1_ Objetivo>. Acesso em: 2 maio 2016.

. Ministério do Trabalho e Emprego. NR 17 - Ergonomia. Brasília: Ministério do Trabalho e Emprego, 1990. Disponível em: <http://trabalho. gov.br/images/Documentos/SST/NR/NR17.pdf>. Acesso em: 2 maio 2016.

. Constituição da República Federativa do Brasil. Promulgada em 5 de outubro de 1988. Disponível em: <http://www.planalto.gov.br/ccivil_03/ constituicao/constituição.htm>. Acesso em: 2 maio 2016.

. Lei n. 5.106, de 2 de setembro de 1966. Dispõe sobre os incentivos fiscais concedidos a empreendimentos florestais. Disponível em: <http:// www.planalto.gov.br/ccivil_03/leis/1950-1969/L5106.htm>.

. Decreto-Lei n. 5452, de 10 de maio de 1943. Aprova a Consolidação das Leis do Trabalho. Diário Oficial (dos) Estados Unidos do Brasil. Poder Executivo. Rio de Janeiro, DF, 9 ago. 1943, seção 1, p. 11937-85.

BRITO, J. O.; BARRICHELO, L. E. G. Recursos químicos e energéticos florestais. Piracicaba: ESALQ, 1978. 46 p.

FENNER, P. T. Métodos de cronometragem e a obtenção de rendimentos para as atividades de colheita de madeira. Notas de aula: disciplina Explotação Florestal. Botucatu: Unesp, 2002. 14 p.

GURGEL GARRIDO, L. M. do A. et al. Estudos matemáticos de alguns componentes de produção diária de resina. Boletim Técnico do Instituto Federal de São Paulo, v. 38, n. 1, p. 47-71, 1984.

LAZIA, B. A Atividade de resinagem envolve operações de risco, o que exige alguns cuidados e equipamentos de segurança para sua execução. Portal agropecuário. mar. 2012. Disponível em: <http://www.portalagropecuario. 
com.br/agricultura/produtos-florestais/saiba-um-pouco- mais-sobre-cultivoe-resinagem-de-pinus/>. Acesso em: 19 maio 2016.

LEITE, Carlos. Resina de Pinus. TGI - Topografia Geoprocessamento Inventário Florestal. dez. 2014. Disponível em: <http://www.florestalegal.com.br/index. php/florestas/pinus/28-resina-de-pinus>. Acesso em: 19 de maio de 2016. POLYQUIM. Processo para extração da goma-resina do pinus. [s.d.]. Disponível em: <http://www.polyquim.com.br/curiosidades.htm>. Acesso em: 19 maio 2016.

RODRIGUES, K.C.S. Resina de pinus no sul do Brasil: caracterização e perspectivas. Revista da madeira, n. 116, set. 2008. Disponível em: <http://www.remade. com.br/br/revistadamadeira_materia.php?num=1317\&subject=Resina $>$. Acesso em: 19 maio 2016.

SILVEIRA, A. M. Saúde do trabalhador. Belo Horizonte: Nescon/UFMG; Coopmed, 2009. Disponível em: <https://www.nescon.medicina.ufmg.br/ biblioteca/imagem/1771.pdf>. Acesso em: 19 maio 2016.

VARELLA, Dráuzio. Privação do sono. abr. 2011. Disponível em: <http:// drauziovarella.com.br/drauzio/privacao-do-sono>. Acesso em: 19 maio 2016. 